\title{
Conferences/Seminars
}

\section{Third Conference of Council of Muslim Librarians and Information Scientists (COMLIS III)}

\author{
Istanbul, Turkey
}

Shawwäli2l-23, 1409/May 24-26. 1989

Istanbul, the seat of the Ottoman Caliphate, was the site of the third meeting of The Council of Muslim Librarians and Information Scientists at Ataturk Cultural Center in the heart of the city. COMLIS, as the acronym implies, is the international professional organization of librarians from Muslim countries and communities, as well as those involved in librarianship in general. At its third meeting seven sessions were held during which a total of 28 papers were delivered. In addition, 48 papers were submitted and included in the published preliminary volume of proceedings of this congress. The seven sessions were titled: The International Muslim Information Network: A Conceptual Framework; Networking Models; Systems Interconnection and Networks; Compatibility and Standardization; Establishing Centers of Excellence in the Muslim World; Telecommunication Requirements, and; Library Cooperation. All of the papers very neatly fitted the theme of the congress, namely "Planning an Information Strategy for the Muslim World." That the congress was held under the auspices of the Turkish Ministry of Culture's Directorate of Libraries and Publications was particularly heartening, for it symbolizes another signal of Turkey's reentry into the mainstream of Muslim nations and communities. The arrangements of the conference were methodical and simultaneous translations of presentations between languages were provided.

Most of the papers concentrated on what is desirable in areas of international cooperation, avoidance of duplication of research, standardization in library technology, and bibliographical practices. No one questions these pious aspirations, but one must go beyond what is desirable to examine what presently exists, and how librarianship and its associated functions can be improved. In one of the sessions many participants addressed these very questions, and indeed made some very sound and practical suggestions. At least two papers - that of Muhammad Ali al-Tasan and Abdussattar Chaudhriboth librarians in Saudi Arabia dealt with practical issues in librarianship as encountered in their institutions. The conclusion one may draw from this particular session was that national economic and political considerations are a big hindrance in the way of library cooperation. Librarians on their 
own cannot remove these roadblocks, for cooperation in librarianship must be preceeded by intensified interaction in other economic and political fields.

Meetings of this nature provide an opportunity for Muslim librarians to share experiences and ideas in their particular field. No matter how improved technologies become, a substitute for face-to-face interaction can never be found. The Congress passed ten resolutions dealing with its recognition as a professional body by the Organization of Islamic Conference, establishment of a secretariat, publication of a journal, and similar other issues.

Omar Khalidi

MIT

Cambridge, MA 